\title{
Exploring Faculty and Staff PA Barriers at a Large University
}

\author{
Bhibha M. Das ${ }^{1}$, Anna I. Rinaldi-Miles ${ }^{2}$, and Ellen M. Evans ${ }^{1}$ \\ ${ }^{1}$ University of Georgia \\ ${ }^{2}$ Illinois State University
}

\begin{abstract}
Introduction: Physical inactivity is a leading cause of morbidity and mortality. Worksites provide an ideal environment for physical activity (PA) interventions. The aim was to use the Nominal Group Technique (NGT) to examine university employees' perceptions of worksite PA barriers and benefits. Methods: A focus group using the NGT and the Health Belief Model was conducted to assess employees' perceived susceptibility of physical inactivity, perceptions of barriers and benefits to PA, and cues to action. Results: Findings showed university employees experienced similar barriers to PA as employees in other sectors, including lack of time and knowledge. Participants reported unique benefits to being physical active, notably being physically active allowed them to maintain demanding professional and personal lifestyles. Discussion: Results imply university employees experienced benefits to PA consistent with other worksite populations; the surprising benefits of PA for this population are strong motivators and would provide an excellent basis for interventions. Results also indicate although university employees face similar barriers to PA as other worksites, the unique barriers for this worksite should be the focus for worksite programs for this population. Similarly to the benefits, the unique barriers of this population should influence development of interventions to promote PA on campuses.
\end{abstract}

(c) 2013 Californian Journal of Health Promotion. All rights reserved.

Keywords: physical activity, universities, Nominal Group Technique, worksites, Health Belief Model, employee wellness

\section{Introduction}

The obesity epidemic continues be one of the greatest public health challenges in contemporary society in the United States. The lack of regular physical activity, combined with poor dietary choices, has resulted in the obesity epidemic. In addition to increased risk for numerous co-morbidities, obesity also has implications for health care costs and employee productivity. Extant research demonstrates that as BMI increases so does the number of sick days (Pronk et al., 2004), and healthcare costs (Wang, McDonald, Champagne, \& Edington, 2004). Importantly, worksites provide an ideal environment for physical activity and weight management programs due to the captive audience, available social support, and the amount of a person's waking hours spent in the work environment.

\section{Worksite Wellness Programs}

Because of the link between lifestyle behaviors and healthcare costs, worksite wellness programs have become a popular method to introduce behavior change programs. A metaanalysis of workplace physical activity interventions have found significant positive effects on physical activity and fitness levels, anthropometric measurements, work attendance and job stress (Conn, Hafdahl, Cooper, Brown, \& Lusk, 2009). It is critical to recognize that there are both significant health and financial benefits for keeping low-risk employees as lowrisk and attempting to lower the risk of mediumand high-risk employees (Makrides et al., 2011). In addition, low-risk employees maintaining their low-risk status may be easier and more cost effective to employers, rather than attempting to change high-risk employees who may lack the motivation, desire, and skills to undergo a 
lifestyle change (Makrides et al., 2011). This working paradigm also captures the "power of primordial prevention," which is aimed at strategies to prevent cardiovascular risk factors, and is a key component in the American Heart Association's 2020 Impact Goals (Lloyd-Jones et al., 2010). Not only do employees' health behaviors influence the workforce's health, but so do the company's work factors, including productivity, time away from work, worker's compensation, absenteeism, and presenteeism (Edington \& Schultz, 2008). Thus an effective health promotion program requires a collaborative partnership between the employee and employer.

Engaging in regular physical activity is a vital component of weight management and chronic disease prevention and management (United States Department of Health and Human Services, 1996, 2008) and is a key component to health promotion programs. A company's environment has the potential to influence employees' health behaviors. Employers that provide programmatic or environmental support for employees to engage in physical activity at the worksite have demonstrated lower rates of health care costs, absenteeism, and presenteeism (Burton, McCalister, Chen, \& Edington, 2005; Engbers, van Poppel, Chin Paw, \& van Mechelen, 2005).

\section{Barriers to Physical Activity}

The barriers to engaging in physical activity are significant reasons individuals do not engage in regular physical activity. According to the Centers for Disease Control and Prevention (2010), the most common reasons given for not engaging in physical activity are the following: 1) not having enough time, 2) being inconvenienced by physical activity, 3) lacking motivation, 4) not finding physical activity enjoyable, 5) finding exercise boring, 6) lacking self-confidence in their ability to be physically active, 7) having the fear of being injured, 8) not having self-management skills, 9) lacking social support, and 10) not having a physical environment conducive to physical activity. Fletcher, Behrens, and Domina (2008) discovered barriers to worksite physical activity programs were different when employees were categorized as either white-collar or blue-collar workers. While "lacking time" was the most common barrier for both groups, scheduling and work conflicts were the most common barriers for time for white-collar employees. For bluecollar employees, however, being required to work shifts (as expected by the nature of their job) was their most common time barrier. Furthermore, mass transit workers' barriers to physical activity included changing work schedules, poor weather conditions, lack of scheduled and timely breaks, and lack of options for being physically active (Escoto et al., 2010; French, Harnack, Toomey, \& Hannan, 2007; Tse, Flin, \& Mearns, 2006). Other research conducted by Taylor et al. (2013) found benefits for physical activity included stress reduction, increased enjoyment, increased health awareness, and improved workplace social interaction while barriers included management support.

\section{Physical Activity among University Employees}

Examining perceived benefits and barriers to physical activity provides insight on the types of interventions that should be implemented to promote physical activity in worksites. Colleges and universities are a unique workplace; not only do faculty and staff comprise a significant portion of any collegiate community, they also provide an opportunity to expose students, our future work force and health care consumers, to positive health modeling.

The academic lifestyle and work-style of the college employees are unique compared to other working populations. Many university employees report working greater than 40 hours per week, including early mornings, late evenings, and even weekends because of the nature of their work, including teaching courses, conducting research, and facilitating research studies. This work is often done without any overtime or financial incentives. University employees also have more varied work hours compared to other employees in other work sectors. Additionally, due to the nature of their work, many faculty and staff members take their work home, blurring the lines between home-life and work-life. 
Most college campuses are highly “walkable’; active transportation, such as walking or biking, could be a key strategy to regular physical activity. While some studies have looked at the impact of worksite wellness programs on university faculty and staff (Byrne et al., 2011), to our knowledge, none have looked at employees' perceptions of benefits and barriers to physical activity on the university campus.

The authors believed perceived barriers and benefits to physical activity would be different in a university community than other worksites, based on the unique schedule of universities (high volumes of work in fall and spring semesters with low volumes of work over winter and summer breaks), along with the abundant availability of resources (e.g. continuing education courses, physical fitness facilities). It is the authors' hope these findings will be used to develop campus-based interventions to promote physical activity. Thus, the aim of this study was to utilize the Nominal Group Technique (NGT), an established qualitative methodological technique, to determine university employees' perceptions of the benefits and barriers to physical activity.

\section{Methods}

\section{Participants}

The authors conducted one focus group to examine employees' perceptions of barriers and benefits to physical activity. The focus group sample consisted of faculty and staff $(\mathrm{n}=10)$ at a large Midwestern university who were recruited via a weekly employee e-newsletter. To be eligible for the study, participants had to be at least part-time employees of the university (defined as at least 20 working hours/week) and at least 18 years of age.

\footnotetext{
Measures

Demographic characteristics Demographic characteristics including sex, age, occupational category, race/ethnicity, marital status, education level, income level, self-reported health status and self-reported physical activity status was also collected. Self-reported health status was assessed using a Likert scale asking participants to rank their overall health from 1 representing "excellent" to 5 representing "poor." Self-
}

reported physical activity was evaluated using a Likert scale asking participants to rank their physical activity from 1 to 5, with 1 representing "not active at all" and 5 representing "extremely active." All participants provided informed consent. This study was approved by the institutional review board of the university.

Focus Group Script and Procedures. The focus group explored barriers to physical activity before, during, and after work. The focus group questions were developed from the Health Belief Model (Glanz, Lewis, \& Rimer, 2002). The Health Belief Model (HBM), a commonly used theory in health education and promotion, was created in the 1950s to examine why medical screening programs were not successful (Hochbaum, 1958). Originally, four perceptions acted as the main constructs of the HBM: perceived seriousness, perceived susceptibility, perceived benefits, and perceived barriers (Glanz, Lewis, \& Rimer, 2002). Recently, the model has included cues to action, motivating factors, and self-efficacy to further explain an individual's health behavior (Glanz, Lewis, \& Rimer, 2002).

The focus group explored the following issues: a) perceived susceptibility of not being physically active, b) perceived seriousness of not being physically active, c) perceived benefits of being physical activity, d) perceived barriers to being physically active, e) self-efficacy to become physically active, and f) cues to action, or techniques that can be used to encourage employees to be physically active.

The Nominal Group Technique (NGT) was used to assess participants' perceptions of physical activity. NGT is a well-established qualitative data collection method (Van de Ven \& Delbecq, 1972; Delbecq, Van de Ven, \& Gustafson, 1975) and was chosen rather than a traditional focus group protocol for several reasons. First, the NGT helps balance participation and influence among all participants (Elliott \& Shewchuk, 2002). In addition, NGT usually generates more creative ideas and a greater number of ideas than traditional focus groups (Delbecq, Van de Ven, \& Gustafson, 1975). Finally, the use of NGT has been demonstrated to result in greater 
satisfaction, greater sense of closure, and a greater sense of accomplishment for participants (Delbecq, Van de Ven, \& Gustafson, 1975).

NGT is a four-step process. In the first step, each participant was provided probing questions that were read by the facilitators and printed on worksheets each participant received, and written on the flip chart at the front of the room. Facilitators provided participants with two minutes to respond to each question. Because the questions were developed from the theoretical framework of the HBM, there were six questions: 1) What is your perceived susceptibility to being physically inactive?; 2) What is your perceived seriousness to not being physically active?; 3) What are the perceived benefits to being physically active?; 4) What are the perceived barriers to being physically active?; 5) What are factors that influence your confidence to being physically active?; and 6) What are steps the university can take to encourage and promote physical activity?. Each participant was asked to think about each question relative to themselves and to their individual and personal situations.

In the next step, group members participated in a "round-robin" feedback session. Each participant was allotted one minute to answer each question on the piece of paper. After each individual answered each question, individuals shared their responses with the group in a roundrobin fashion. The facilitators wrote the responses, verbatim, on the flip chart at the front of the room. In the third step, each recorded idea was discussed briefly (1-2 minutes) to clarify and evaluate the idea. Since many answers repeated themselves, steps 2 and 3 were relatively brief. Finally, each individual voted on the priority of the ideas and the themes; then a mutual decision was based on the vote. For each question, participants ranked the top three ideas or themes from the total, generated list of ideas and themes. The focus group lasted approximately 60 minutes. The focus group was digitally audio-taped and transcribed.

\section{Statistical Analyses}

Focus group demographic data was summarized using descriptive statistics. Focus group data was transcribed from the focus group audiotape. Since part of the NGT protocol requires participants to rank the top three ideas or themes from the total generated list of ideas and themes, this information was already coded on flip charts provided in the focus group. This data coded and summarized to provide final results, which also included frequencies of participants who provided a response that was categorized into each of the top three themes/ideas.

\section{Results}

\section{Demographic Characteristics}

Ten faculty and staff members, varying in demographic and occupational status, from a large, research university participated in the focus group. A good balance of males (60\%) and females (40\%) comprised this study. Average age of participants was $46.5 \pm 10.9$ years with the age range (33-64 years) being representative of the employees. Similarly, the ethnic/racial breakdown was reflective of the employee population. Notably, 70\% identified themselves as academic professionals, $20 \%$ as faculty, and $10 \%$ as civil service. At this university, academic professionals included employees whose titles included research coordinator and research scientist while civil service included secretarial, informational technology, and custodial staff.

The sample was highly educated, as expected given the employer, with 30\% having doctoral degrees, 20\% having master's degrees, $40 \%$ having a bachelor's degree, and $10 \%$ having an associate's degree. With the relatively higher socioeconomic status, it was also not surprising that $80 \%$ of the sample reported their overall health status as good or excellent while 50\% reported their general level of physical activity as fairly active or extremely active. Ninety percent of the sample reported having children; with $60 \%$ of the sample reported having children under the age of 18 years who lived at home and needed some type of parental support. In addition, $50 \%$ of the sample reported having to care for both children and for aging parents.

All employees reported working more than 40 hours per week, including early mornings, late 
evenings, and even weekends due to the nature of their work, including preparing or teaching classes or coordinating research studies. Fifty percent of employees reported working 41-50 hours per week, 30\% reported working 51-60 hours per week, and 20\% reported working between 61-70 hours per week. Although we had two participants who had nine-month faculty appointments, these faculty members stated they received summer salary, essentially working twelve months, due to research and teaching demands.

\section{Perceived Susceptibility}

According to the HBM, "perceived susceptibility" is defined as one's beliefs of being at risk of developing a disease or condition. Perceived susceptibility has been noted as a significant factor in prompting individuals to change health behaviors. Our findings (Table 1) determined that faculty and staff's perceived susceptibility to being physically inactive were 1 ) a relapse of prior disabilities and ailments (i.e. chronic conditions) due to physical inactivity, 2) fear of the inability to maintain good health and a good quality of life, and 3) fear of loss of mental focus, especially during the work day. One participant mentioned, "In my early 20s and 30s, I didn't take good care of my health and had some serious health issues. Now, I know the importance of taking care of myself so I don't have to depend on others but also so I don't get sick again. While another stated, "I don't want to just live long, I want to live well, too.”

\section{Perceived Seriousness}

"Perceived seriousness" is defined as one's beliefs about the seriousness or severity of the disease (Glanz, Lewis, \& Rimer, 2002). It has also been defined in the literature as one's beliefs of the seriousness or severity of not engaging in a specific health behavior, such as practicing safe sexual practices (Glanz, Lewis, \& Rimer, 2002) or in this case physical inactivity. Although often the perceived seriousness is founded on scientific knowledge, it can also be influenced by an individual's personal beliefs about the difficulties and the effects the disease or condition would have on one’s life (Edlin \& Golanty, 2009).
From the round-robin discussion and voting, participants' consensus for perceived seriousness of being physically inactive included 1) the risk of becoming weak and physically incapable (i.e. physical disability); 2) the risk of developing other related co-morbidities, including diabetes and heart disease; and 3) not being able to be there for one's children and loved ones due to related complications and comorbidities (Table 1). One individual stated, "I want to get off my blood pressure medicine or at least lower the amount I need to take. My doctor keeps telling me if I do more exercise, I can at least lower the amount I take." Another individual mentioned, "I am a young parent and the main breadwinner for the family; if I am sick, who will take care of my family?” Also, some individuals cared not only for their children but their aging parents, which may have influenced their perceived seriousness to physical inactivity.

\section{Perceived Benefits}

"Perceived benefits" can be defined as one's belief in the value of a new health behavior in decreasing the risk of disease development or improving quality of life (Glanz, Lewis, \& Rimer, 2002). It is well documented that individuals are more likely to engage in healthy behaviors if they believe it will help decrease their risks of developing disease.

University faculty and staff reported the following as their perceived benefits of being physically active: 1) better mental condition, being alert, and having more energy, especially at work, 2) better ability to participate in extracurricular activities and engage in family and peer bonding, and 3) better management of challenging life schedules, including management of challenging professional and personal responsibilities (Table 1). One participant stated, "I want to have energy for my kids.” Another participant remarked, "I don't work a normal 9-5 job. Some days I'm in the office from 7 am to noon, then I volunteer at my son's school for a few hours and then I come back and teach an evening class. If I weren't active, I wouldn't be able to keep up with my chaotic schedule.” 
Table 1

Nominal Group Technique Findings Based on the Health Belief Model

Perceived Susceptibility:

1) A relapse of prior disabilities and ailments due to physical inactivity $(n=9)$

2) Fear of the inability to maintain good health and good quality of life $(n=8)$

3) Fear of loss of mental focus, especially during the work day $(n=6)$

Perceived Seriousness:

1) Risk of becoming weak and physically incapable (i.e. physical disability) $(n=9)$

2) Risk of developing other related co-morbidities $(n=8)$

3) Not being able to be there for one's children and loved ones $(n=7)$

Perceived Benefits:

1) Better mental condition, being alert, and having more energy, especially at work $(n=10)$

2) Better ability to participate in extra-curricular activities and engage in family and peer bonding ( $\mathrm{n}=8$ )

3) Better management of challenging life schedules, including management of professional and personal responsibilities $(n=7)$

Perceived Barriers:

1) Lack of access and choices in facilities $(n=7)$

2) Time management and inflexible work schedules $(n=6)$ Self-Efficacy:

3) Lack of knowledge regarding campus choices for physical activity $(n=4)$

1) Not knowing specifically what to do to be physically active $(n=8)$

2) Not knowing how much physical activity is required to be healthy and to prevent chronic diseases $(n=7)$

3) Not knowing how to eat properly to engage in physical activity $(n=6)$ Cues to Action:

1) Adding a social component to physical activity programs $(n=9)$

2) Creating walking paths on campus $(n=8)$

3) Creating physical activity challenges and competitions with incentives $(n=5)$

\section{Perceived Barriers}

"Perceived barriers" is one's beliefs about the obstacles present from adopting a new health behavior (Janz \& Becker, 1984). Perceived barriers have been identified as one of the most important tenets of the HBM because barriers pose the most significant factor in determining behavior change. The participants identified the perceived barriers to being physically active in the university setting as the following: 1) lack of access and choices in facilities, 2) time management and inflexible work schedules, and 3) lack of knowledge regarding campus choices for physical activity (Table 1). All participants reported working over 40 hours each week, which included early mornings, late evenings, and weekends. One participant stated, "A lot of times I work till 6 or 7 on Friday evenings and then I have to be back to check cultures at 7 or 8 on Saturday and Sunday mornings. You really don't get too much of a break from work but it's the nature of research." Another participant reported, "I work in IT (information technology) and when a faculty member is breathing down your neck because he needs his computer working ASAP, it is hard to pack up and leave at
5 on the dot. You stay till the job is done and sometimes that is till 8 or 9 at night or sometimes you have to come back on the weekends.” One participant stated, “I don't really get a break, or at least it doesn't feel like it. Sometimes I have to stay late to run samples and then be back early the next morning to check our samples," while another participant reported, “The research doesn't end on the weekends. It's actually when we do a lot more of it because there are fewer people around so you can usually find me here on Saturdays and Sundays." A participant started, "My work schedule seems to be the biggest factor weighing me down right now. I know I'll feel better if I exercise but right now, my schedule is all over the place."

\section{Self-Efficacy}

"Self-efficacy" has been defined as an individual's belief in his/her ability to succeed in task specific situations (Bandura, 1977; Bandura, 1997). An individual's self-efficacy plays a pivotal role in one's goals, tasks, and challenges (Bandura, 1977; Bandura, 1997). Participants reported not being confident about 
their ability to be physically active for the following reasons: 1) not knowing specifically what to do to be physically active, 2) not knowing how much physical activity is required to be healthy and to prevent chronic diseases, and 3) not knowing how to eat properly to engage in physical activity (Table 1). One participant responded, "I have to re-think what counts as physical activity because sometimes I don't know what I need to do or not. I don't even know what you're supposed to do for physical activity because there are too many conflicting messages out there.”

\section{Cues to Action}

The HBM states that health behaviors are influenced by "cues to action", which are defined as events, people or things that motivate people to change their behaviors (Glanz, Lewis, \& Rimer, 2002). Participants were asked, "What are steps the university can take to encourage and promote physical activity?" Participants' responses were: 1 ) adding a social component to physical activity programs, 2) creating walking paths on campus, and 3) creating physical activity challenges and competitions with incentives (Table 1). One participant mentioned, "The lack of social support has been hard for me" while another responded, "I know I need support just to stay on track. It's really easy for me not to want to do anything." These comments demonstrate the importance of adding a social component to physical activity programs to foster social support.

\section{Discussion}

Faculty and staff are a vital part of the college or university work community. Not only do they provide invaluable service to the community within higher education, but they also serve as health models for students, our future work force. However, their health needs, particularly those needing extensive behavior changes such as increasing physical activity, are often overlooked by campus health and human resources services. To our knowledge, this is one of the first studies evaluating university employees' perceptions of physical activity using the framework of the HBM and the NGT focus group technique. The use of the NGT focus group is novel in health behavior research since it has only been previously used for assessment of African-Americans' perceptions of the healthiness of cultural food items (Jefferson et al., 2010).

Our main findings suggest that although our sample of faculty and staff were physically active and had high self-rated health status compared to other studies assessing differing populations (Parks, Housemann, \& Brownson, 2003; Salmon, Owen, Crawford, Bauman, \& Sallis, 2003), they still expressed concern regarding the perceived severity and susceptibility of physical inactivity. Notably, many of their stated ramifications were related to their job performance (i.e. fatigue) and managing their multiple roles (i.e. work-life balance). Additionally, several key barriers to being physically active within the campus community were identified, which can aid intervention efforts for this unique worksite venue.

\section{Perceived Susceptibility}

To our knowledge, no study has assessed physical inactivity susceptibility and seriousness in worksites using the HBM. However, several studies have looked at the HBM for assessing physical inactivity susceptibility and seriousness in adults. Similar to our findings, other studies have reported participants' susceptibility to physical inactivity were due to fear of reporting negative health outcomes and improving quality of life (Kasser \& Kosma, 2012; Suggs, McIntyre, \& Cowdery, 2010). Because this study's participants have challenging, unconventional work schedules, the finding of "fear of loss of mental focus, especially during the work day" was unique to this population and one would expect to see this finding again, if the study were repeated in other universities. This finding demonstrates that mental health and stamina were just as important as physical health for these participants. Future interventions targeted at this population should focus not only on the physical health benefits of physical activity but the mental health ones as well.

\section{Perceived Seriousness}


For the construct of "perceived seriousness," other studies reported similar findings of developing a physical disability or becoming weak (Kasser \& Kosma, 2012) and developing chronic disease, such as heart disease and diabetes (Al-Ali \& Haddad, 2004). The third theme of "not being able to be there for one's children and loved ones" was not surprising since all participants reported being either a parent or a caregiver of some sort. Again, this finding demonstrates that individuals are motivated to be physically active not only from a physical health perspective but from other viewpoints, including providing security and support for their families. Interventions targeted at this population should focus on participants understanding benefits to physical activity that transcend purely physical health ones.

\section{Perceived Benefits}

In alignment with understanding the seriousness of physical inactivity for their health, our results indicate participants' perceived benefits, while similar to other benefits of physical activity reported in the literature (Middlestadt, Sheats, Geshnizjani, Sullivan, \& Arvin, 2011), are different based on the unique expectations and constraints of this particular worksite. One of the most surprising results from this study was one of the perceived benefits was "better management of challenging life schedules." Because the majority of the participants were classified as either faculty or academic professionals, their work schedules were not a typical 9am to 5pm, Monday through Friday schedule. Many of them worked over forty hours a week and had other personal obligations to fulfill, as well. Additionally, participants reported working from home, blurring the lines between home-life and work-life. Participants reported that being physically active helped them lead an overall healthy life, which in turn helped with management of these challenging life schedules, including the blending of homelife and work-life. As this "ability to cope" concept is a proximal benefit compared to a distal benefit (i.e. prevention of heart disease), it may be an important construct for maintaining adherence.

\section{Perceived Barriers}

Our results indicate that the perceived barriers to physical activity on campus are similar to barriers at worksites. A qualitative study conducted by Escoffery, Kegler, Alcantara, Wilson, and Glanz (2011) reported barriers in a rural worksite to be lack of access in facilities and time management. This finding is also corroborated by a study done by Schwetschenau, O'Brien, and Jex (2008) that found corporations with on-site fitness centers reported low usage because the accessibility hours were inconvenient. The same study reported that time management and inflexible work schedules were barriers to physical activity during work hours. Participants in the same study reported, "My job demands don't allow me to take the time." (2008, p. 375).

The most common perceived barriers to physical activity on campus were 1) better access and choices in facilities, 2) better time management \& more flexible work schedules, and 3) better knowledge of resources for campus choices for physical activity. These barriers are similar to barriers reported in other studies (Anderson et al., 2009; Escoffery, Kegler, Alcantara, Wilson, \& Glanz, 2011). However, because of the particular worksite, participants did report one barrier, which was unique to this setting. Participants reported one of the major barriers to physical activity on campus was "better access and choices in facilities." Since this particular university is large and spread out, individuals who worked in a particular section of the campus were upset that there was no gym or other place for physical activity located nearby, resulting in a 20-30 minute walk. However, the use of the walking time and distance could be incorporated into the physical activity program.

\section{Self-Efficacy}

Participants' beliefs about their knowledge of physical activity influencing their self-efficacy to be physically active were also similar to those reported in literature (Osborn, Paasche-Orlow, Bailey, \& Wolf, 2011; Williams \& French, 2011). For many participants, not knowing the specifics of how to increase their physical activity impaired their self-efficacy for physical activity. As Umstattd, Baller, Blunt, and Darst (2011) reported, increases in employees' self- 
efficacy enabled them to incorporate walking as a means of active transport, something they were unaware of how to do specifically to be physically active. Participants' beliefs about their self-efficacy can be used to develop social marketing techniques and behavior change programs to address these specific issues.

\section{Cues to Action}

Participants named several cues to action to foster a more physically active working environment. Participants requested adding a social component such as creating intramural sports or walking groups. Clearly marked walking paths on campus, denoting the distance, along with hosting physical activity competitions with incentives were additional suggestions for facilitating a physical activity program for staff and faculty at a large university. These cues to action are welldocumented in the literature as being critical to increasing physical activity in worksites (Engbers, van Poppel, Chin Paw, \& van Mechelen, 2005). Participants especially emphasized the importance of adding a social component because the work culture of the university often is segregated by departments and within departments by laboratory groups. Adding a social component would help with integration of different departments and units within the university and help with fostering a positive work community.

\section{Limitations}

Although this pilot study had strengths, there were several limitations that may have impacted outcomes. The first major limitation of this study is the variability in demographics of the focus group participants. The college campus is a unique worksite, with employees falling into a wide educational spectrum, from high school graduates to doctoral degrees. However in our sample, $50 \%$ of participants possessed a graduate degree and $90 \%$ identified as being either an academic professional or faculty member, positions requiring at least a four-year degree. Finally, $80 \%$ of focus group participants self-identified as Caucasians. Having a more diverse sample in regards to educational status, employee classification, and race may have resulted in different perceptions.

Second, health status and physical activity information were self-reported. Future research should use a mixed methods research design, combining quantitative and qualitative work, to develop and extend our findings. Also, the small size of the focus group is a limitation; however, the small size did allow the researchers to encourage open and honest participation from participants and allowed for the collection of detailed data that may not have happened in larger focus groups. Despite these limitations, these findings provided meaningful, translatable data for physical activity promotion and intervention design for university employees.

\section{Conclusion}

Although faculty and staff are an integral component of the college community, their health needs are often overlooked by campus health services. Findings from this study demonstrated that faculty and staff expressed a unique barrier to physical activity (e.g., physical disability), and a unique outcome of physical inactivity (e.g., loss of mental focus). The most notable perceived barrier for this population was lack of time management skills and inflexible work schedules. Meaningful cues to action for this population include adding a social component, such as developing walking groups, or hosting physical activity competitions with incentives, to foster social support. Future studies should include conducting focus groups stratified by job classification (e.g. academic professional, faculty, and staff) along with implementing and evaluating campus-wide health communications campaign using social marketing based on this study’s findings.

\section{References}

Al-Ali, N., \& Haddad, L. G. (2004). The effect of the health belief model in explaining exercise participation among Jordanian myocardial infarction patients. Journal of Transcultural Nursing, 15, 114-121.

Anderson, L. M., Quinn, T. A., Glanz, K., Ramirez, G., Kahwati, L. C., Johnson, D. B., Katz, D. L. (2009). The effectiveness of worksite nutrition and physical activity interventions for controlling 
employee overweight and obesity: A systematic review. American Journal of Preventive Medicine, 37, 340-357.

Bandura, A. (1997). Self-efficacy: The exercise of control. New York: W. H. Freeman.

Bandura, A. (1977). Social Learning Theory. New York: General Learning Press.

Burton, W. N., McCalister, K. T., Chen, C., \& Edington, D. W. (2005). The association of health status, worksite fitness center participation, and two measures of productivity. Journal of Occupational and Environmental Medicine, 47, 343-351.

Byrne, D. W., Goetzel, R. Z., McGown, P. W., Holmes, M. C., Beckowski, M. S., Tabrizi, M. J., Yarbrough, M. I. (2011). Seven-year trends in employee health habits from a comprehensive workplace health promotion program at Vanderbilt University. Journal of Occupational and Environmental Medicine, 53, 1372-1381.

Centers for Disease Control and Prevention. (2010). Promoting physical activity: A guide for community action (2nd ed.). Champaign, IL: Human Kinetics Publishers, Inc.

Conn, V. S., Hafdahl, A. R., Cooper, P. S., Brown, L. M., \& Lusk, S. L. (2009). Meta-analysis of workplace physical activity interventions. American Journal of Preventive Medicine, 37, 330339.

Delbecq, A. L., Van de Ven, A. H., \& Gustafson, D. H. (1975). Group techniques for program planning: A guide to nominal group and delphi processes. Glenview, IL: Scott, Foresman, and Company.

Edington, D. W., \& Schultz, A. B. (2008). The total value of health: A review of literature. International Journal of Workplace Health Management, 1, 8-19.

Edlin, G., \& Golanty, E. (2009). Health and wellness (9th ed.). Boston, MA: Jones and Bartlett Publishers.

Elliott, T. R., \& Shewchuk, R. M. (2002). Using the Nominal Group Technique to identify the problems experienced by persons living with severe physical disabilities. Journal of Clinical Psychology in Medical Settings, 9(2), 65-76.

Engbers, L. H., van Poppel, M. N., Chin Paw, M., \& van Mechelen, W. (2005). Worksite health promotion programs with environmental changes: A systematic review. American Journal of Preventive Medicine, 29, 61-70.

Escoffery, C., Kegler, M. C., Alcantara, I., Wilson, M., \& Glanz, K. (2011). A qualitative examination of the role of small, rural worksites in obesity prevention. Preventing Chronic Disease, 8, A75.

Escoto, K. H., French, S. A., Harnack, L. J., Toomey, T. L., Hannan, P. J., \& Mitchell, N. R. (2010). Work hours, weight status, and weight-related behaviors: A study of metro transit workers. International Journal of Behavioral Nutrition and Physical Activity, 7, 91-97. doi: 10.1186/1479-5868-7-91

Fletcher, G. M., Behrens, T. K., \& Domina, L. (2008). Barriers and enabling factors to work-site physical activity programs: A qualitative examination. Journal of Physical Activity and Health, 5, 418429.

French, S., Harnack, L., Toomey, T., \& Hannan, P. (2007). Association between body weight physical activity and food choices among metropolitan transit workers. International Journal of Behavioral Nutrition and Physical Activity, 4, 52-57. doi: 10.1186/1479-5868-4-52

Glanz, K., Lewis, F. M., \& Rimer, B. K. (2002). Health Behavior and health education. San Francisco, CA: Jossey-Bass.

Hochbaum, G. M. (1958). Public participation in medical screening programs: A socio-psychological study. Washington, DC: United States Government Printing Office.

Janz, N. K., \& Becker, M. H. (1984). The Health Belief Model: A decade later. Health Education Quarterly, 11, 1-47.

Jefferson, W. K., Zunker, C., Feucht, J. C., Fitzpatrick, S. L., Greene, L. F., Shewchuk, R. M., Ard, J. D. (2010). Use of the Nominal Group Technique (NGT) to understand the perceptions of the healthiness of foods associated with African Americans. Evaluation and Program Planning, 33, 343-348. 
Kasser, S. L., \& Kosma, M. (2012). Health beliefs and physical activity behavior in adults with multiple sclerosis. Journal of Disability Health, 5, 261-268.

Lloyd-Jones, D. M., Hong, Y., Labarthe D., Mozaffarian, D., Appel, L. J., Van Horn, L., Rosamond, W. D. (2010). Defining and setting national goals for cardiovascular health promotion and disease reduction. Circulation, 121, 586-613.

Makrides, L., Smith, S., Allt, J., Farquharson, J., Szpifogel, C., Curwin, S.,...Edington, D. (2011). The Healthy Lifeworks Project: A pilot study of the economic analysis of a comprehensive workplace wellness program in a Canadian government department. Journal of Occupational and Environmental Medicine, 53, 799-805

Middlestadt, S. E., Sheats, J. L., Geshnizjani, A., Sullivan, M. R., \& Arvin, C. S. (2011). Factors associated with participation in worksite wellness programs: Implications for increasing willingness among rural service employees. Health Education and Behavior, 38, 502-509.

Osborn, C. Y., Paasche-Orlow, M. K., Bailey, S. C., \& Wolf, M. S. (2011). The mechanisms linking healthy literacy to behavior and health status. American Journal of Health Behavior, 35, 118128.

Parks, S. E., Housemann, R. A., \& Brownson, R. C. (2003). Differential correlates of PA in urban and rural adults of various socioeconomic backgrounds in the United States. Journal of Epidemiology and Community Health, 57, 29-35.

Pronk, N. P., Martinson, B., Kessler, R. C., Beck, A. L., Simon, G. E., \& Wang, P. (2004). The association between work performance and physical activity, cardiorespiratory fitness, and obesity. Journal of Occupational and Environmental Medicine, 46, 19-25.

Salmon, J., Owen, N., Crawford, D., Bauman, A., \& Sallis, J. F. (2003). PA and sedentary behavior: A population-based study of barriers, enjoyment, and preference. Health Psychology, 22, 178-188.

Schwetschenau, H. M., O’Brien, W. H., Cunningham, C. J., \& Jex, S. M. (2008). Barriers to PA in an onsite corporate fitness center. Journal of Occupational Health Psychology, 13, 371-380.

Suggs, L. S., McIntyre, C., \& Cowdery, J. E. (2010). Overweight and obese sedentary adults' physical activity beliefs and preferences. American Journal of Health Studies, 25, 69-77.

Taylor, W. C., King, K. E., Shegog, R., Paxton, R. J., Evans-Hudnall, G. L., Rempel, D. M.,Yancey, A. K. (2013). Booster breaks in the workplace: Participants' perspectives on health-promoting work breaks. Health Education Research, in press. Epub ahead of print retrieved March 11, 2013, from http://her.oxfordjournals.org/content/early/2013/03/06/her.cyt001.long

Tse, J. L. M., Flin, R., \& Mearns, K. (2006). Bus driver well-being review: 50 years of research. Transportation Research, 9, 89-114.

Umstattd, M. R., Baller, S. L., Blunt, G. H., \& Darst, M. L. (2011). Correlates of perceived worksite environmental support for PA. Journal of Physical Activity and Health, Suppl2, S222-S227.

United States Department of Health and Human Services. (1996). Physical activity and health: A report of the Surgeon General. Atlanta, GA: Centers for Disease Control and Prevention.

United States Department of Health and Human Services. (2008). 2008 physical activity guidelines for Americans. Washington, D.C.: United States Department of Health and Human Services.

Wang, F., McDonald, T., Champagne, L. J., \& Edington, D. W. (2004). Relationship of body mass index and physical activity to health care costs among employees. Journal of Occupational and Environmental Medicine, 46, 428-436.

William, S., \& French, D. P. (2011). What are the most effective intervention techniques for changing physical activity self-efficacy and physical activity behavior and are they the same? Health Education Research, 26, 308-322.

Van de Ven, A. H., \& Delbecq, A. L. (1972) .The effectiveness of nominal, delphi, and interacting group decision making processes. Academy of Management Journal, 17, 605-621. 


\author{
Author Information \\ *Bhibha M. Das, PhD, MPH \\ University of Georgia \\ Department of Kinesiology \\ 330 River Road \\ Athens, GA 30602 \\ Email: bhibha@uga.edu \\ Telephone: 706-688-9297 \\ Anna I. Rinaldi-Miles, PhD \\ Illinois State University \\ Department of Kinesiology and Recreation \\ Ellen M. Evans, PhD \\ University of Georgia \\ Department of Kinesiology \\ * corresponding author
}

